\title{
Effects of Prenatal Education on Maternal and Neonatal Outcomes in High Risk Pregnant Women
}

\section{Farzaneh Rahimi $^{1, *}$, Fariba Islami ${ }^{2}$, Mohamad Mehdi Kahangi ${ }^{3}$}

${ }^{I}$ Nursing \& Midwifery Sciences Development Research Center, Najafabad Branch, Islamic Azad University, Najafabad, Iran.Midwifery, Amiralmomenin Hospital, Shahreza, Isfahan University of Medical Sciences, Isfahan, Iran

${ }^{2}$ MSc, Nursing, Faculty of Nursing and Midwifery, Islamic Azad University, Isfahan Branch (Khorasgan), Isfahan, Iran

* Corresponding Author: Farzaneh Rahimi, Nursing and Midwifery Sciences Development Research Center, Department of Midwifery, Najafabad Branch, Islamic Azad University, Najafabad, Iran. Email: rahimi.farz@yahoo.com

\begin{tabular}{|c|c|}
\hline & Abstract \\
\hline $\begin{array}{l}\text { Received: } 08 / 06 / 2016 \\
\text { Accepted: } 08 / 02 / 2018\end{array}$ & \multirow[b]{2}{*}{$\begin{array}{l}\text { Background and Objective: Lack of awareness and the fear of women is } \\
\text { one of the reasons for cesarean delivery and the occurrence of } \\
\text { complications in maternal and neonatal period in our country. This study } \\
\text { was conducted to investigate the effect of prenatal education on maternal } \\
\text { and neonatal outcomes in high risk pregnant women. } \\
\text { Materials and Methods: The present study was done as a randomized } \\
\text { clinical trial on } 150 \text { high risk pregnant women was referred to } \\
\text { Amiralmomenin Hospital in Shahreza, Iran in } 2014 \text {. Samples were } \\
\text { randomly assigned to control and intervention groups. The control group } \\
\text { only received routine pregnancy care and case group received routine } \\
\text { pregnancy care and prenatal education. After delivery, Maternal and } \\
\text { neonatal outcomes including type of delivery, Apgar index, weight and } \\
\text { height, head circumference, and jaundice were assessed by using Chi- } \\
\text { square and independent t-test. } \\
\text { Results: Intervention and control groups did not significant in terms of } \\
\text { demographic and obstetric variables ( }>>0 / 05) \text {. The results showed that a } \\
\text { significant difference between two groups in type of delivery, height } \\
\text {,weight and head circumference ( }<0 / 001) \text {. However there was no } \\
\text { significant difference between the two groups in Apgar scores and in } \\
\text { jaundice (P }>0.05 \text { ). } \\
\text { Conclusion: raising awareness and education of pregnant women during } \\
\text { pregnancy promote and improve the health of the baby and be a natural } \\
\text { delivery. Therefore, it is suggested that prenatal education more widely } \\
\text { used. }\end{array}$} \\
\hline $\begin{array}{l}\text { How to Cite this Article: } \\
\text { Rahimi F, Islami F, Kahangi } \\
\text { MM. Effects of Prenatal } \\
\text { Education on Maternal and } \\
\text { Neonatal Outcomes in High risk } \\
\text { Pregnant Women. Pajouhan } \\
\text { Scientific Journal. 2018; 16(3): } \\
\text { 48-57. DOI: } 10.18869 / \mathrm{psj} .16 . \\
\text { 3.48 }\end{array}$ & \\
\hline & $\begin{array}{l}\text { Keywords: Education; High Risk Pregnant Women; Maternal; Newborn; } \\
\text { Outcome }\end{array}$ \\
\hline
\end{tabular}




\section{بررسى ثأثير آموزشهاى دوران باردارى، بر يامدهاى مادرى و نوزادى در زنان باردار تروه يرخطر}

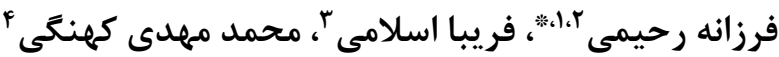

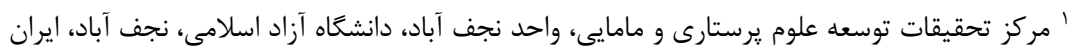

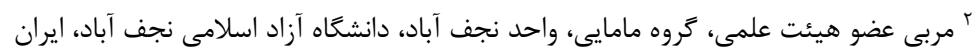

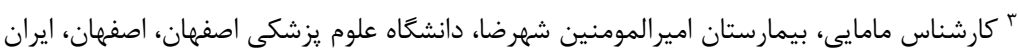

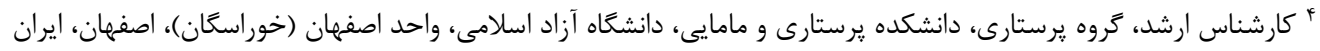
* * نويسنده مسئول: فرزانه رحيمى، كروه مامايى، واحد نجف آباد، دانشكاه آزاد اسلامى نجف آباد، ايران.

ايميل: Rahimi.farz@yahoo.com

\begin{tabular}{|c|c|}
\hline جكيده & \\
\hline سابقه و هدف: عدم آكاهى و ترس زنان يكى از دلايل افزايش سزارين و عوارض مادرى و دوره نوزادى & 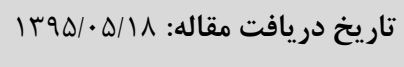 \\
\hline است. هدف از يُرهش حاضر تعيين تأثير آموزشهاى دوران باردارى، بر ييامدهاى مادرى و نوزادى در زنان & 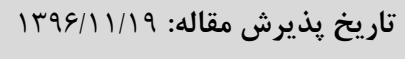 \\
\hline باردار كروه يرخطر بود. & \\
\hline مواد و روشها: يُوهش حاضر به روش كارآزمايى بالينى تصادفى، برروى •هازن باردار كروه برخطر & بز شمكى همدان محفوظ نشر است. دانشاه علوم \\
\hline مراجعه كننده به بيمارستان اميرالمؤمنين شهرضا در سال \&qجا انجام شد. نمونهها به طور تصادفى در دو & \\
\hline كروه و مداخله و كنترل قرار گرفتند. گروه كنترل فقط مراقبتهاى معمول دوران باردارى و كروه مداخله & \\
\hline مراقبت هاى معمول دوران باردارى به همراه آموزشهاى دوران باردارى را دريافت مى كردند. در نهايت بعد از & \\
\hline زايمان بيامد مادرى و نوزادى در هر دو كروه از جمله نوع زايمان، ضريب آيخار، وزن، قد، دورسر و زردى & \\
\hline نوزادى با استفاده از آزمون تى مستقل و كاى دو اندازهذيرى شد. & \\
\hline يافته ها: دو كروه مداخله و كنترل از نظر متغيرهاى دموكرافيك و مامايى تفاوت آمارى معنى دارى نداشتند & \\
\hline (P> (P> ). بين نوع زايمان، وزن، قد و دورسر نوزادان كروه مداخله در مقايسه با كروه كنترل تفاوت آمارى & \\
\hline 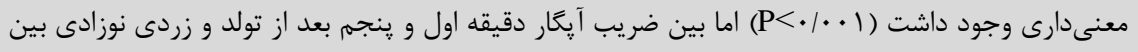 & \\
\hline دو َروه تفاوت آمارى معنى دارى مشاهده نشد (ه>•/P>). & \\
\hline نتيجه كيرى: افزايش آكاهى و آموزشهاى دوران باردارى به زنان باردار كروه برخطر، موجب ارتقاو بهبود & \\
\hline سلامتى نوزادان و افزايش زايمان طبيعى شود. از اين رو بيشنهاد مىشود كه از آموزشهاى دوران باردارى & \\
\hline به طور كستردهترى استفاده شود. & \\
\hline وازَّان كليدى: آموزش؛ پيامد؛ زنان بارداريرخطر؛ مادرى؛ نوزاد & \\
\hline
\end{tabular}

دارد [r]. عدم آكاهى و ترس باعث ايجاد اضطراب مادران

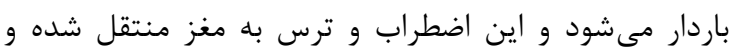

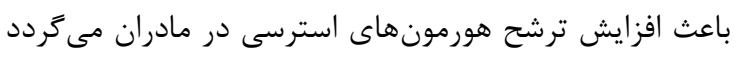

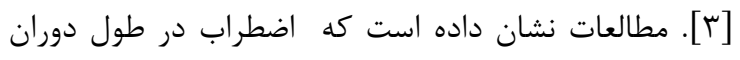

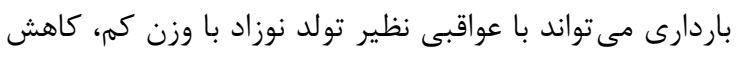

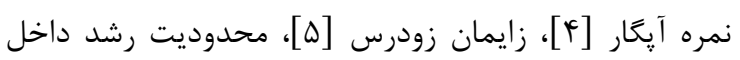

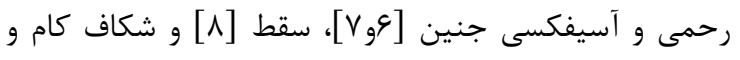

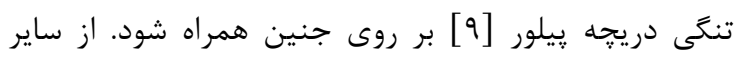

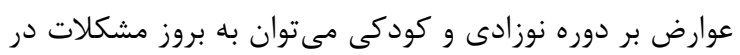

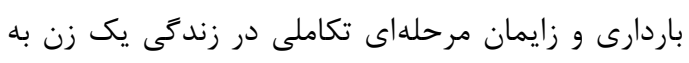

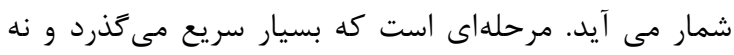

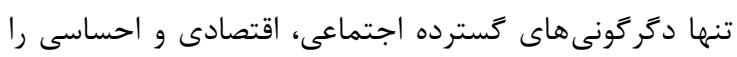

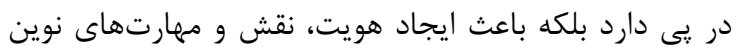

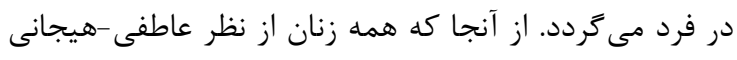

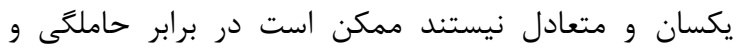

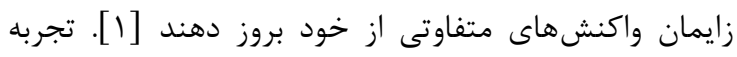

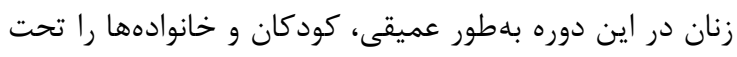

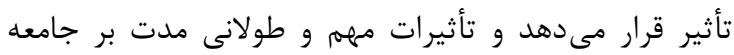


زايمان است [YT]. اين كلاسها فرصت مغتنمى را فراهم

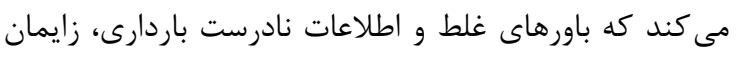

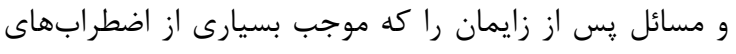

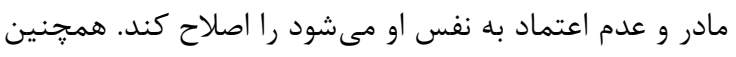

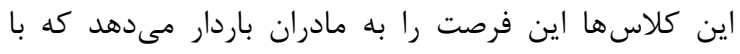

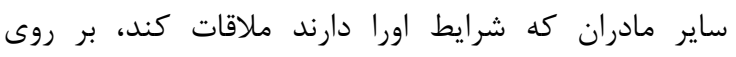
نيازهاى شخصى و اهدافش تفكر و تمركز كند؛ درنتيجه

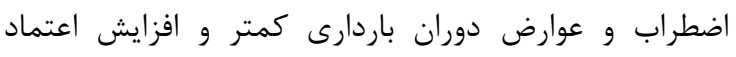

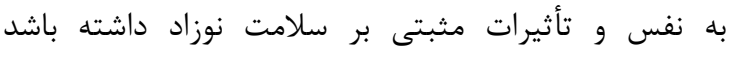

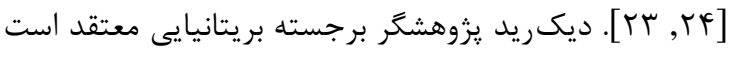

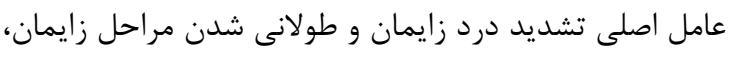

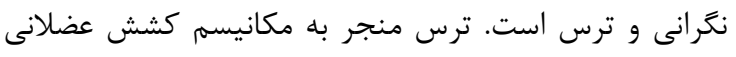

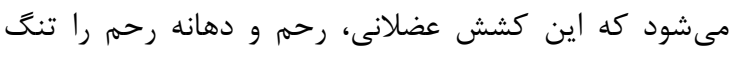

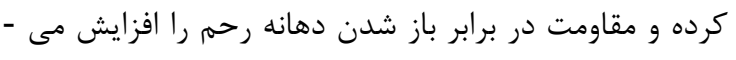

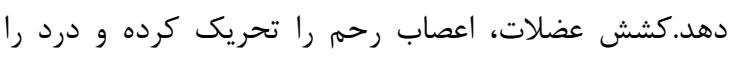

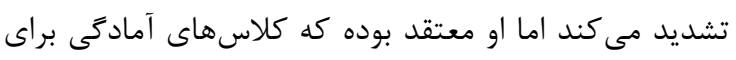

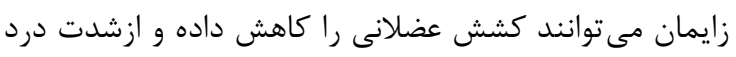

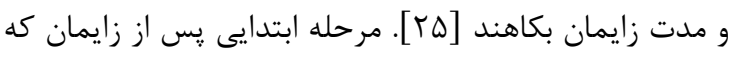

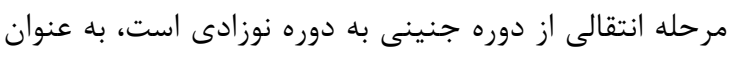

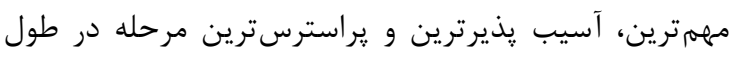

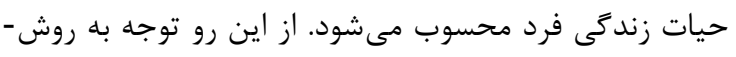

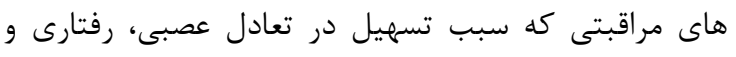

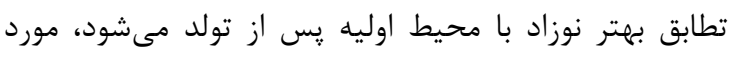

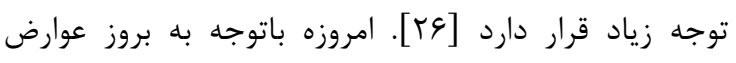

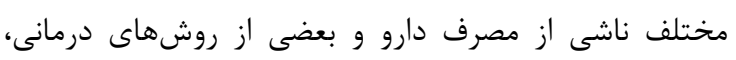

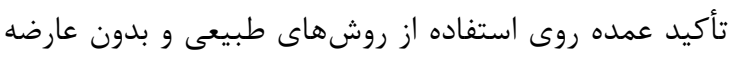

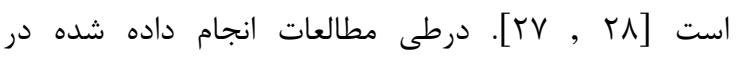

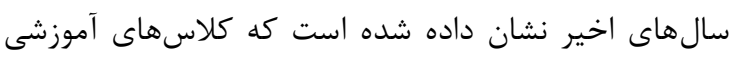

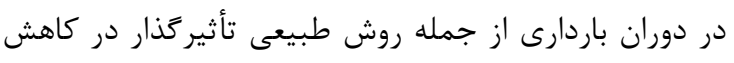

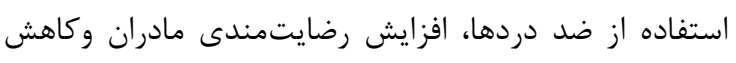

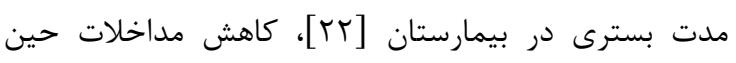

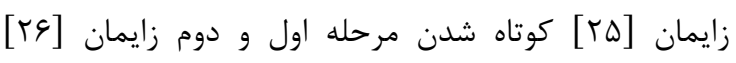

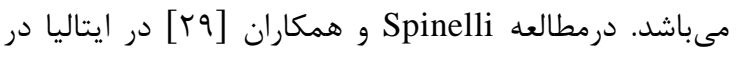

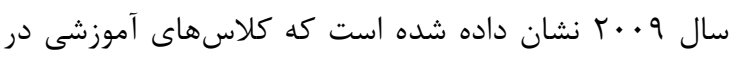

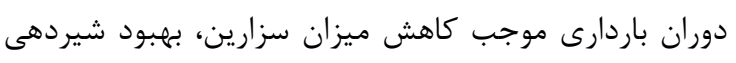

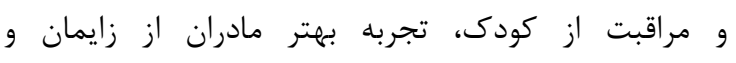

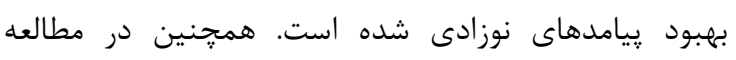
Ferguson

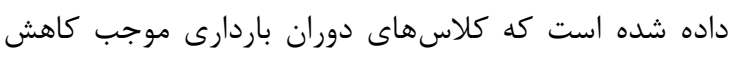

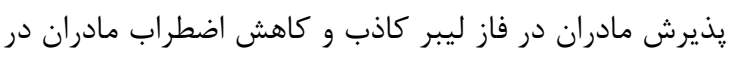

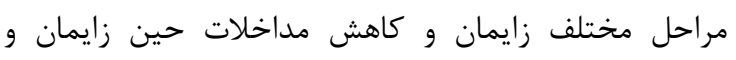

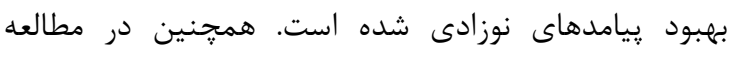
Susan

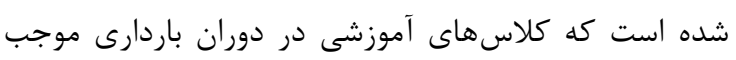

سلامت روان كودكان [• [1]، بيش فعالى، تحريك يذيرى، بد

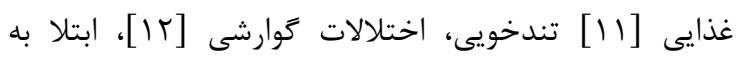

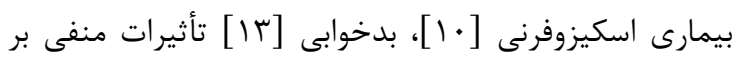

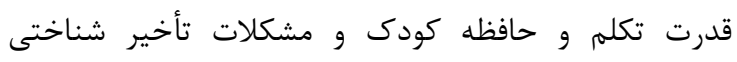

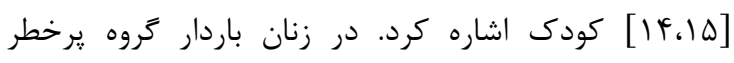

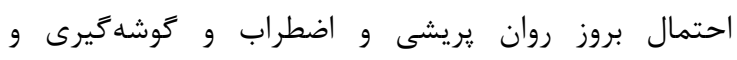

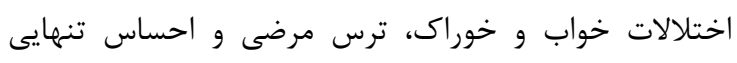

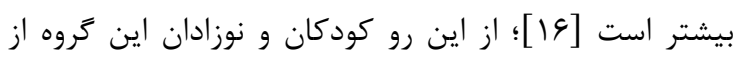

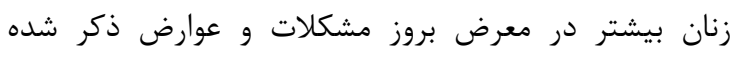

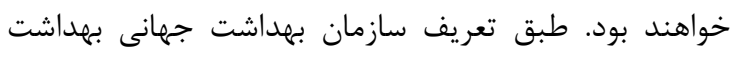

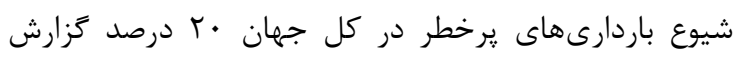

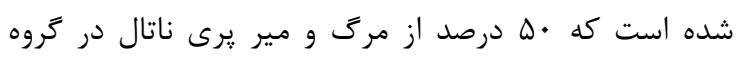

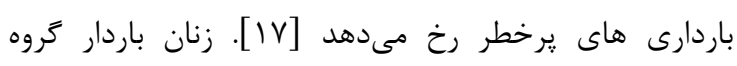

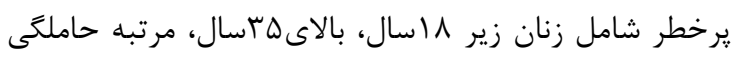

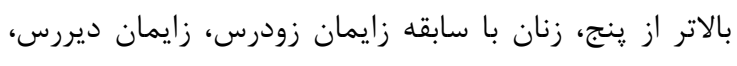

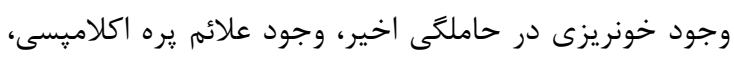

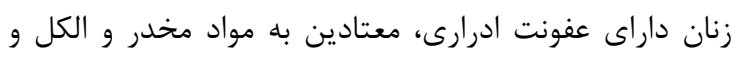

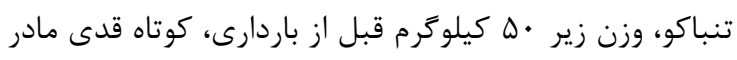

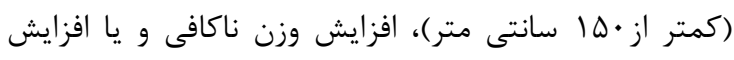

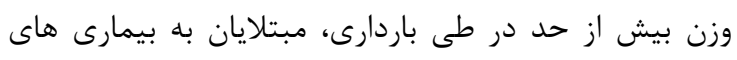

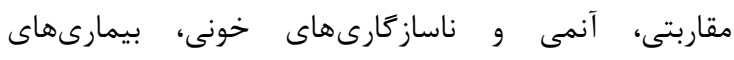

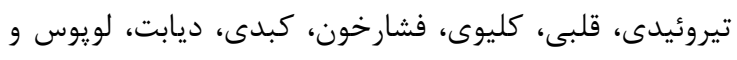

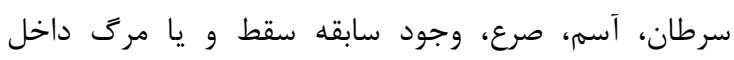

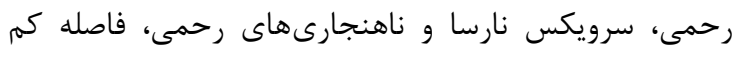

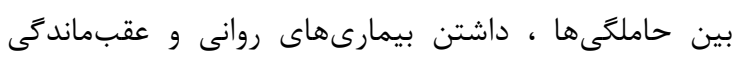

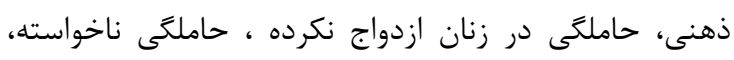

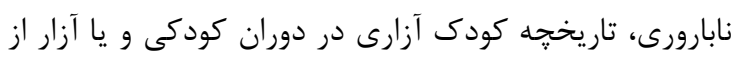

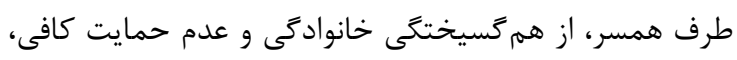

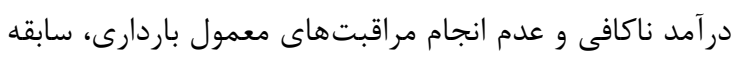

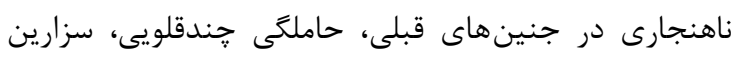

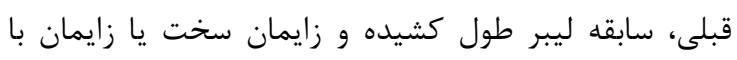

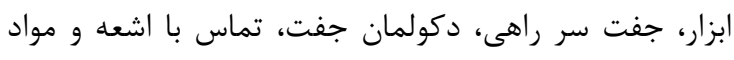

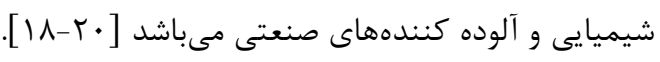

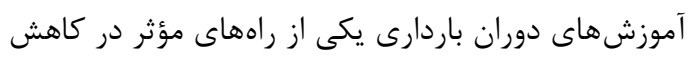

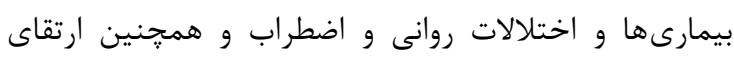

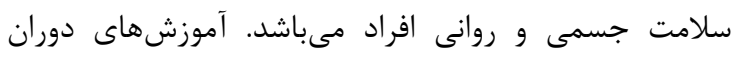

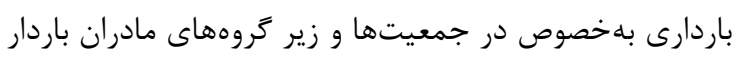

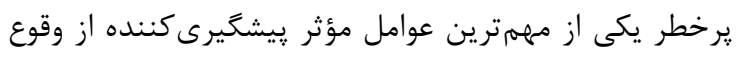

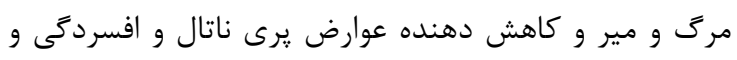

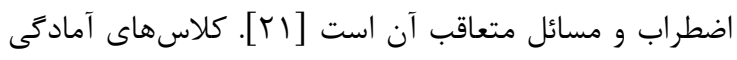

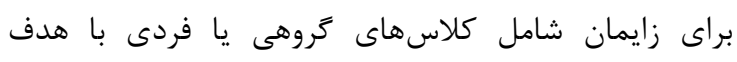

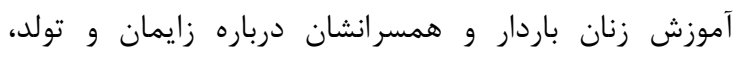

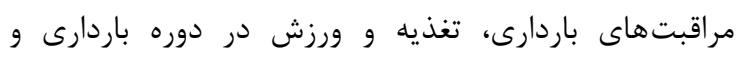

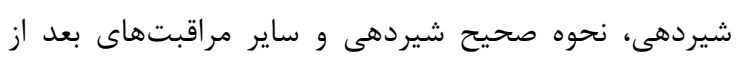


درنهايت • لا نمونه وارد مطالعه شدند. معيارهاى خروج

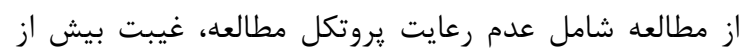

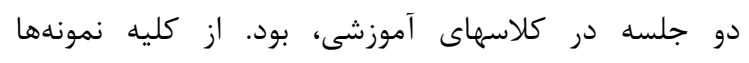

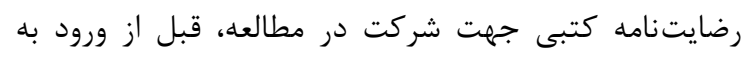

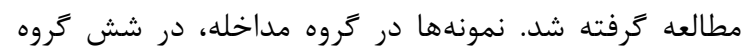

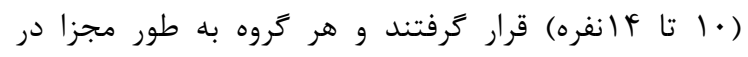

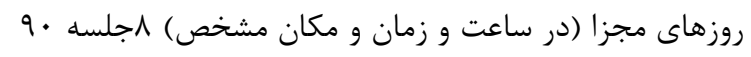

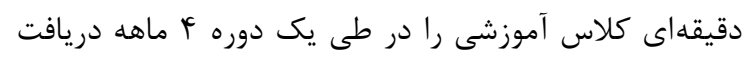

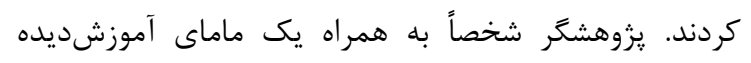

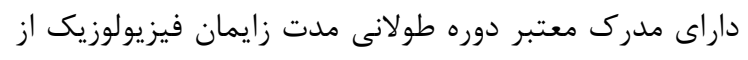

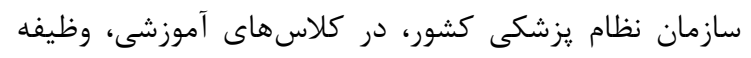

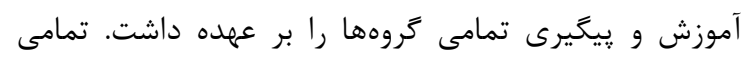

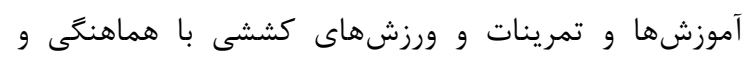
مشورت با يزشك معالج و يا يزشك مراكز بهداشتى - درمانى

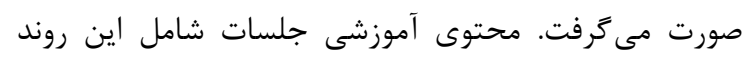

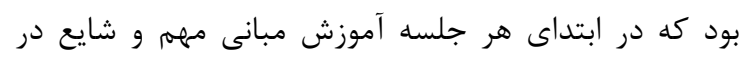

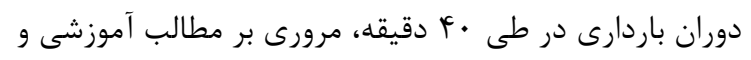

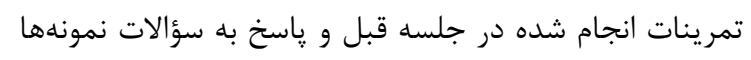

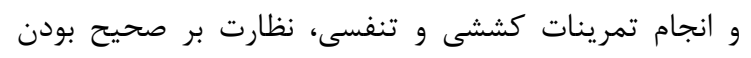

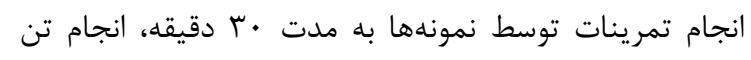

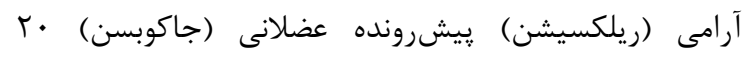
دقيقه بود. در جلسات آموزشى از تمامى زنان باردار خواسته

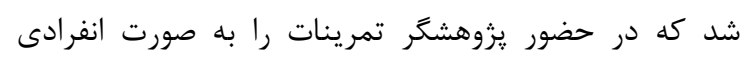

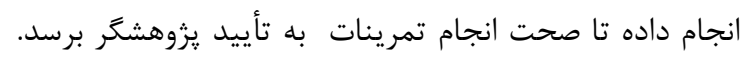

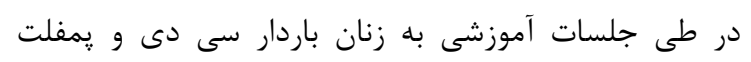

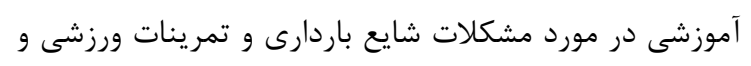

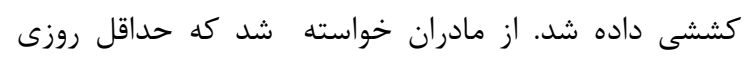

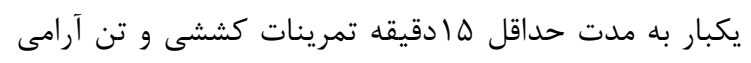

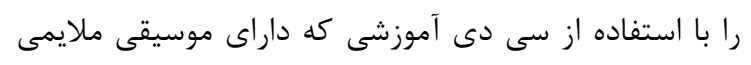

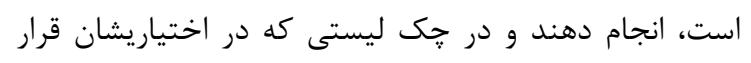

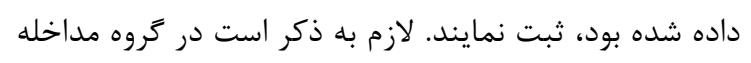

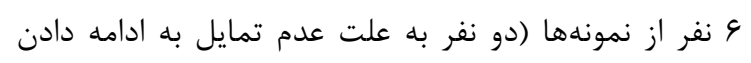

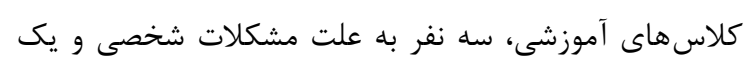

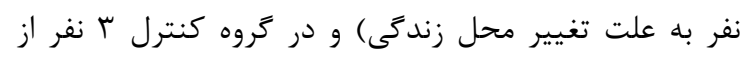

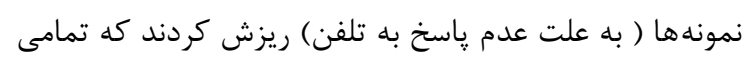

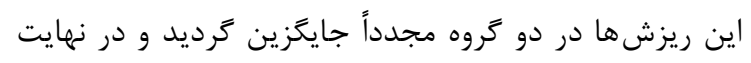

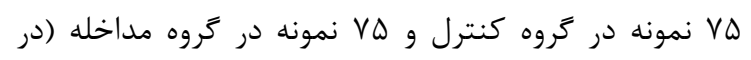

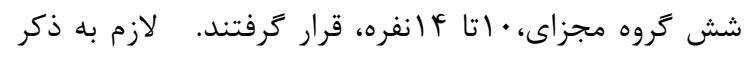

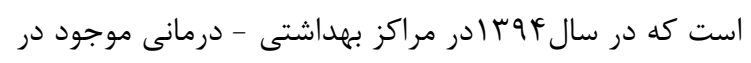

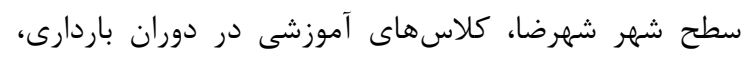

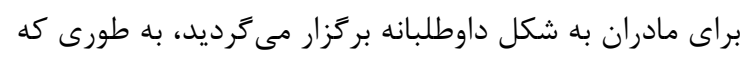

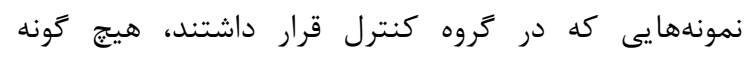

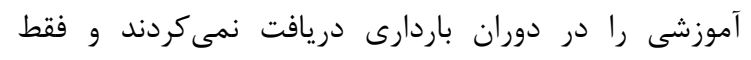

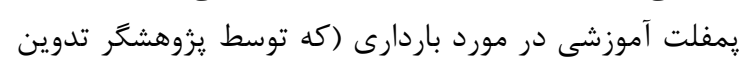

كاهش ميزان سزارين و كاهش نياز به بى حسى إيدورال و

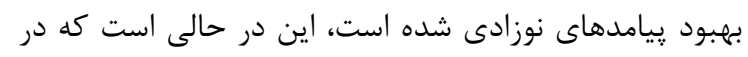

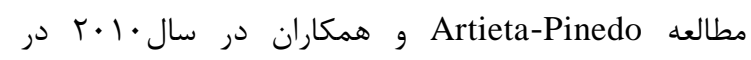

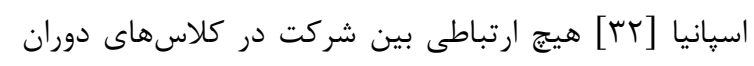

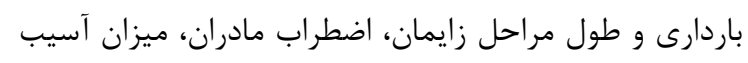

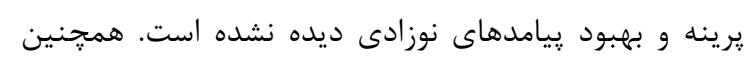

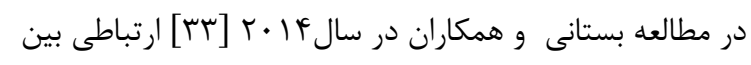

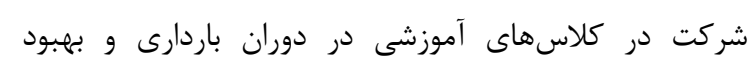

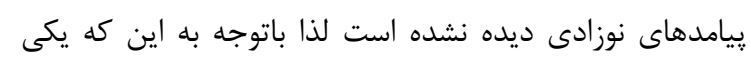

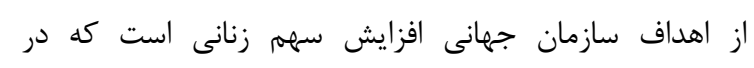

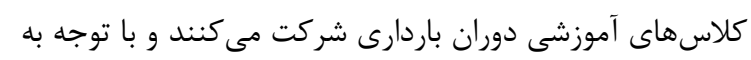

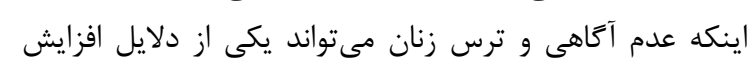

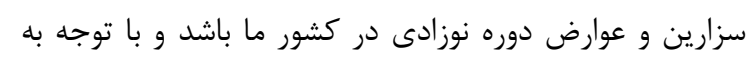

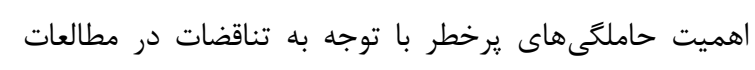

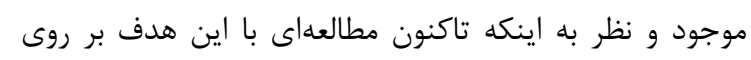

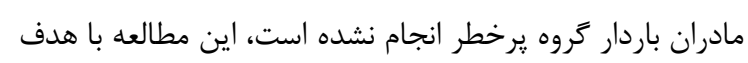

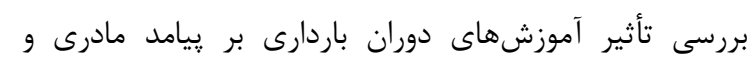
نوزادى در زنان باردار كروه يرخطر طراحى نر درديد.

\section{مواد و روشها}

اين مطالعه به روش كارآزمايى بالينى تصادفى، در مراكز

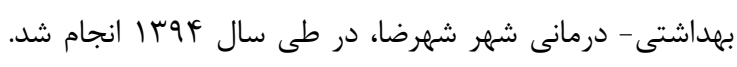

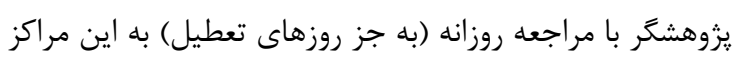

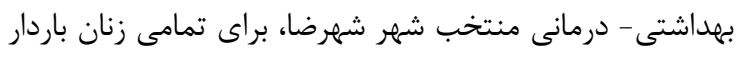

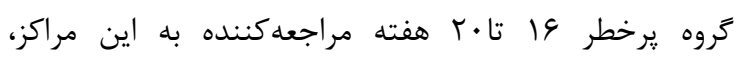

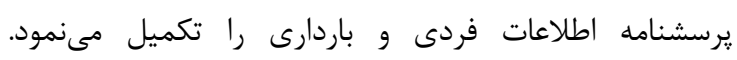
نمونههايى كه تمايل شركت در مطالعه داشته و معيارهاى نظير

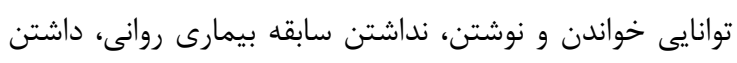

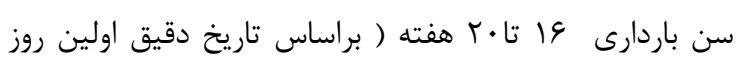

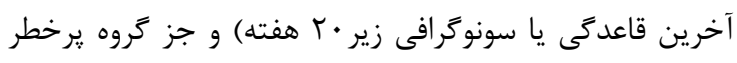

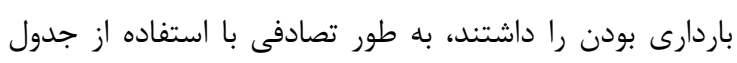

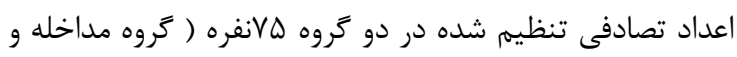

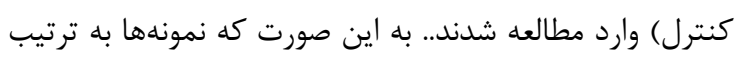

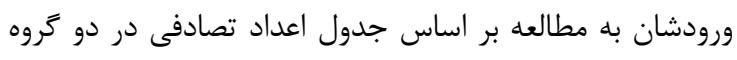

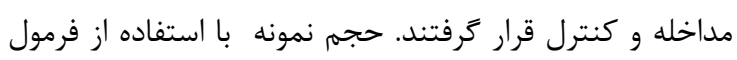
زير •له انمونه ، برآورد گرديد.

$$
\begin{aligned}
& n \geq \frac{\left(z_{\alpha / 2}+z_{\beta}\right)^{2} \sigma^{2}(1+1 / k)}{\varepsilon^{2}} \\
& 1-\beta=0.80 \Rightarrow z_{\beta}=0.84 \text { توان آزمون } \\
& \theta=\text { اندازه اثر } \\
& \text { نسبت نمونه دردو كروه تجربى و كنترل }
\end{aligned}
$$

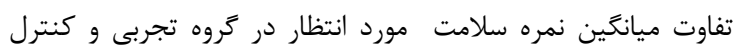
$\varepsilon=\mu_{1}-\mu_{2}$ 


$$
\text { بالينى ايران ثبت كرديده است. }
$$

\section{يافته ها}

در اين مطالعه دو كروه از نظر مشخصات فردى و مامايى

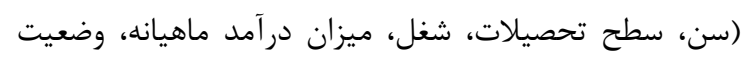

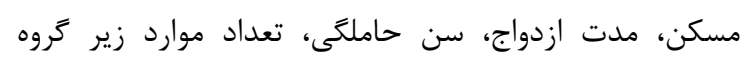

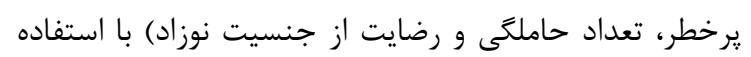

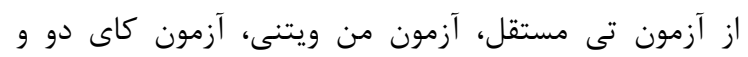

$$
\text { دقيق فيشر همغن بودند (جدول (آ ). }
$$

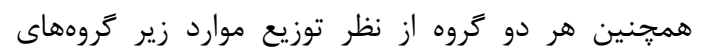

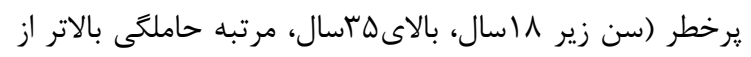

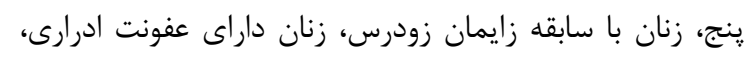

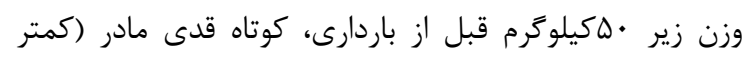

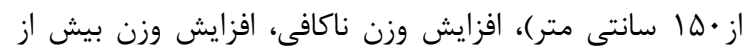

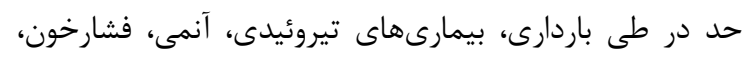

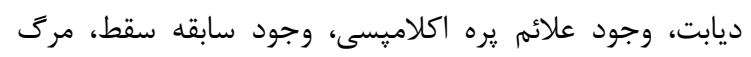

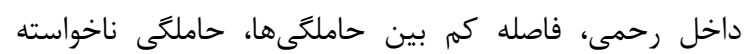

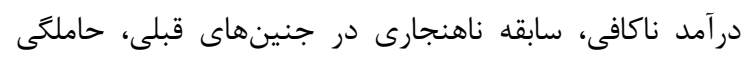

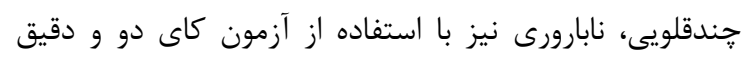

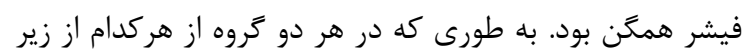

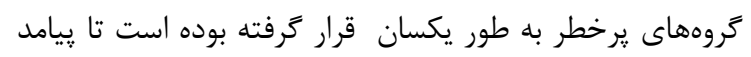

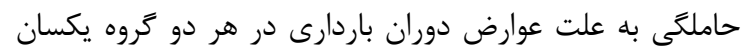

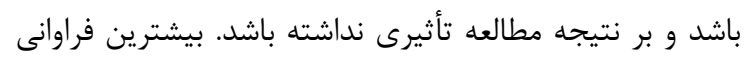

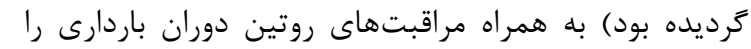

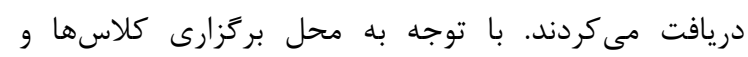

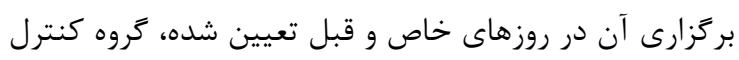

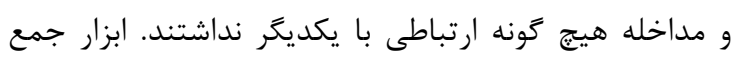

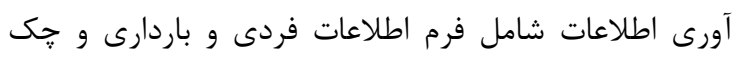

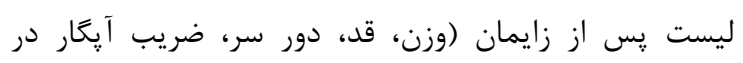

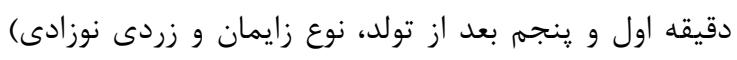

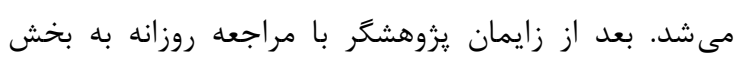

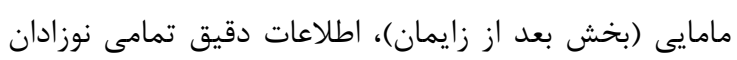

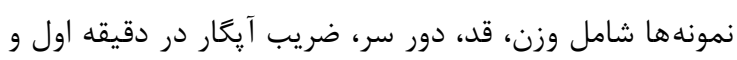

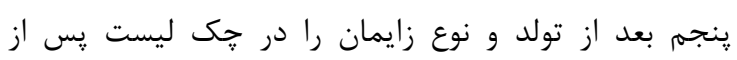

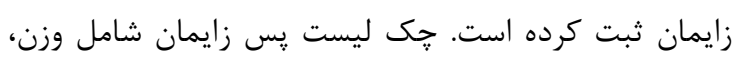

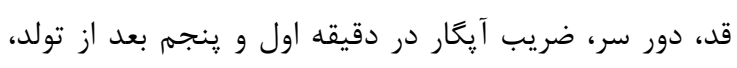

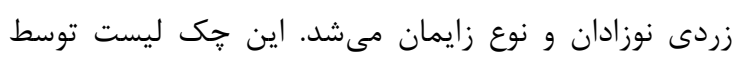

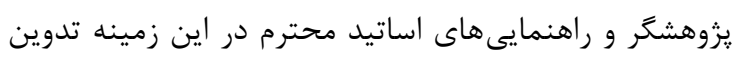

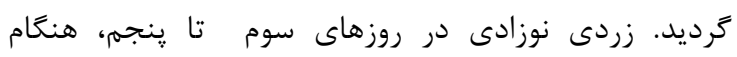

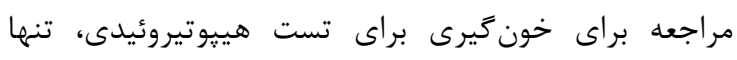

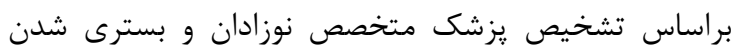

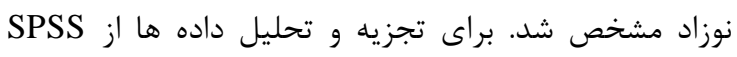

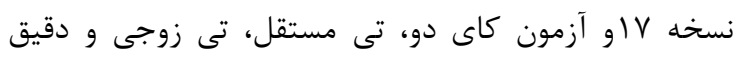

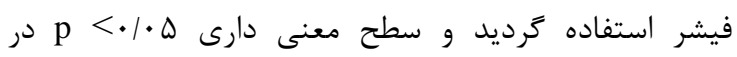

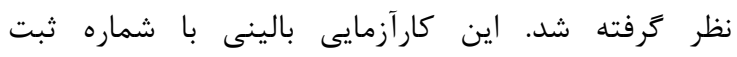
در سايت كارآزمايى هاى داره

جدول ا: توزيع متغيرهاى فردى مامايى در دو كروه مداخله و كنترل

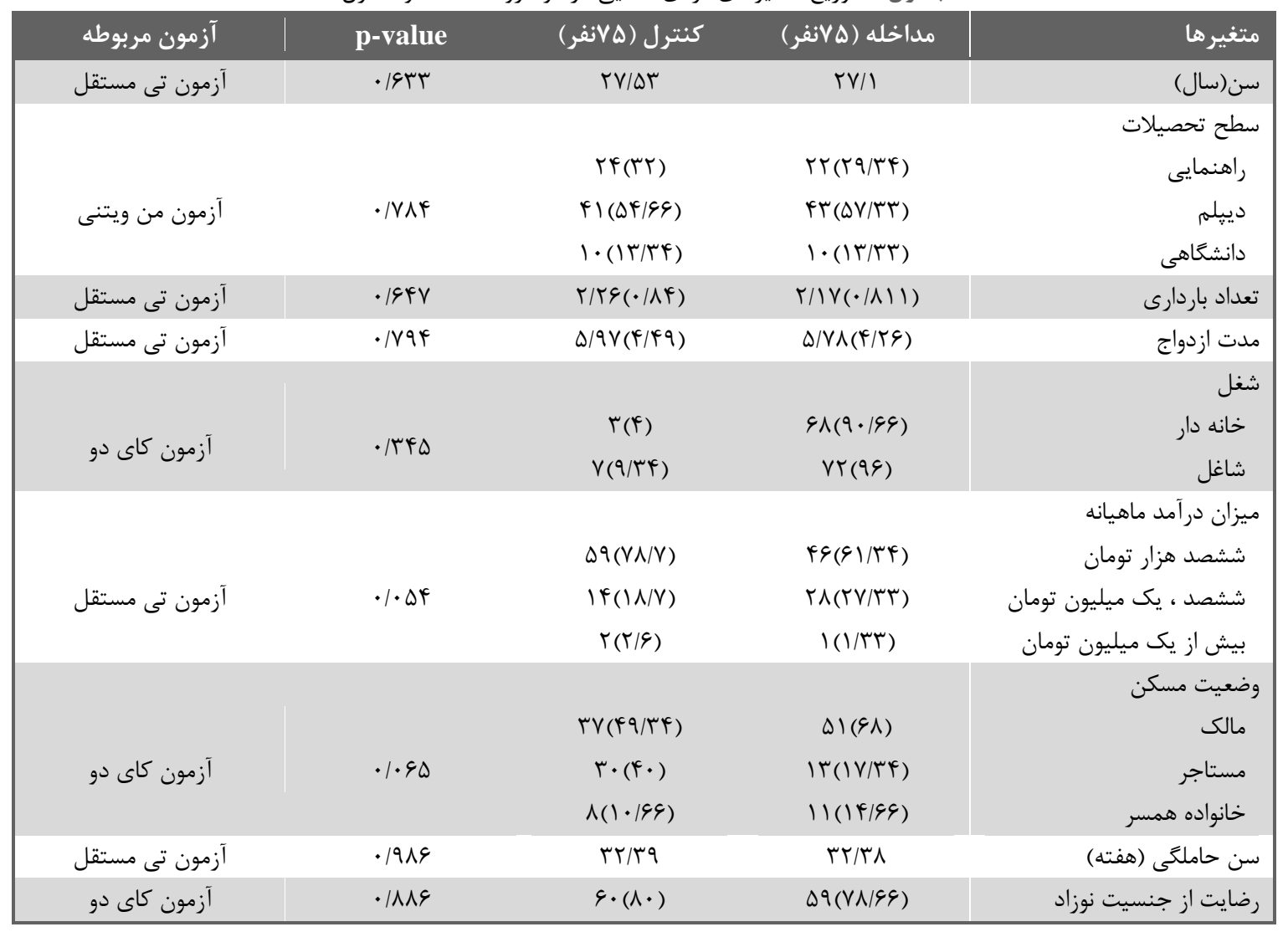


در بررسى تعدادى از ييامدهاى مادرى و نوزادى در اين

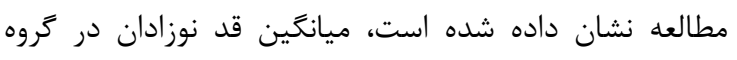

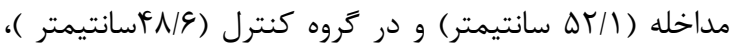

به ترتيب در موارد، وجود سابقه سقط و عادرصد، حاملكى داري

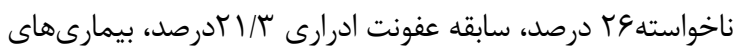

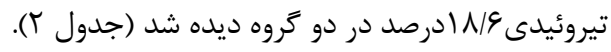

جدول ז: توزيع فراوانى موارد مختلف زير كروه هاى يرخطر در كروه مداخله و كنترل

\begin{tabular}{|c|c|c|c|c|c|c|c|}
\hline \multirow{2}{*}{ آزمون مربوطه } & \multicolumn{2}{|c|}{ جمع } & \multicolumn{2}{|c|}{ كنترل } & \multicolumn{2}{|c|}{ مداخله } & \multirow{2}{*}{ شتراخصه } \\
\hline & ل درصد & ت ت تعداد & در ل درد & ت تعداد & د مرصد & ت تعداد & \\
\hline $\begin{array}{l}\text { آزمون كاى دو } \\
\text { (p-value=1 ) }\end{array}$ & re & $\Delta F$ & re & rr & بq & $r V$ & وجود سابقه سقط \\
\hline 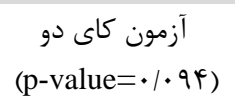 & rs & rq & rt & rF & $r \cdot$ & 10 & حاملكَى ناخواسته \\
\hline 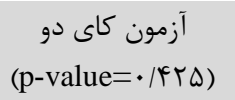 & $r \mid r$ & rt & IN/99 & If & re & 11 & سابقه عفونت ادرارى \\
\hline $\begin{array}{l}\text { آزمون كاى دو } \\
\text { (p-value=1 }\end{array}$ & $|N| 9$ & rı & $1 N / 99$ & if & IN/99 & if & بيمارى هاى تيروئيد \\
\hline 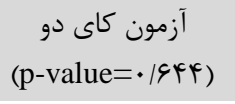 & $\mid F / V$ & rt & 19 & ir & r & 1. & باردارى زير · هكيلوكرم قبل از \\
\hline 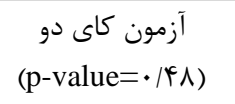 & If & r) & 19 & ir & ir & 9 & سن بالاى هـ"سال \\
\hline 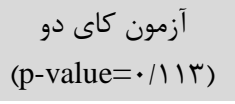 & 1.19 & 19 & 9199 & $\Delta$ & $19 / 99$ & 11 & دورايش وارن بيش ازحد در \\
\hline $\begin{array}{c}\text { آزمون كاى دو } \\
(p-v a l u e==• \mid \Delta f V)\end{array}$ & $\wedge$ & it & T/r & v & 9199 & $\Delta$ & دوران باردارى وزن ناكافى در طى \\
\hline $\begin{array}{l}\text { آزمون دقيق فيشر } \\
\text { (p-value=1 }\end{array}$ & 4 & 9 & 9199 & $\Delta$ & D L & r & \\
\hline 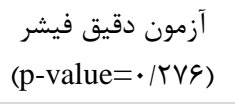 & $\Delta / r$ & $\wedge$ & $\wedge$ & 9 & $r / 99$ & r & فاصله كم بين حاملكى ها \\
\hline 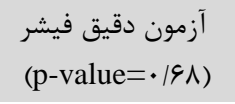 & 4 & 4 & $r / 99$ & $r$ & D/r & r & فشارخون \\
\hline $\begin{array}{l}\text { آزمون دقيق فيشر } \\
\text { (p-value=I ) }\end{array}$ & r & 4 & r & r & r & r & سابقه زايمان زودرس \\
\hline 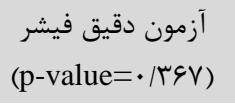 & $r / 4$ & $\Delta$ & 1/r & 1 & D/rr & r & سابقه نابارورى \\
\hline 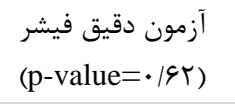 & $r / V$ & r & r & r & 1/r & 1 & ديابت باردارى \\
\hline $\begin{array}{l}\text { آزمون دقيق فيشر } \\
\text { (p-value=1 }\end{array}$ & r/9 & r & $r / 99$ & r & $r / 99$ & r & سن زير | السال \\
\hline 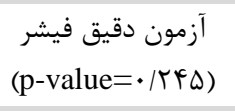 & $r$ & r & r & r & . & . & قد مادر كمتر از • ها سانتى \\
\hline $\begin{array}{l}\text { آزمون دقيق فيشر } \\
(p-v a l u e=1)\end{array}$ & r & r & 1/r & 1 & T/99 & r & سابقه مركى داخل رحمى \\
\hline 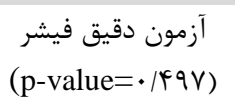 & $1 / \pi$ & r & · & . & $r / 99$ & r & وجود علائم بره اكلاميسى \\
\hline $\begin{array}{c}\text { آزمون دقيق فيشر } \\
\text { (p-value=1) }\end{array}$ & $1 / 4$ & r & $1 / \pi$ & 1 & $1 / \pi$ & 1 & حاملكى حند قلويى \\
\hline $\begin{array}{c}\text { آزمون دقيق فيشر } \\
\text { (p-value=1) }\end{array}$ & $\cdot / V$ & 1 & זr/1 & 1 & . & . & سابقه ناهنجارى در جنين \\
\hline
\end{tabular}


در كروه كنترل (ميزان سزارين سٓ/سه درصد و زايمان

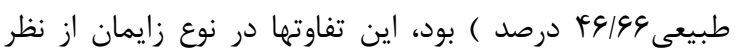

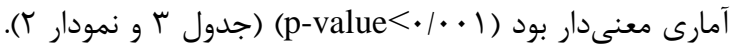

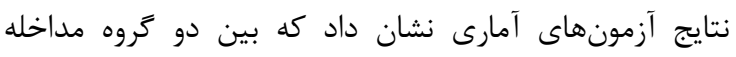

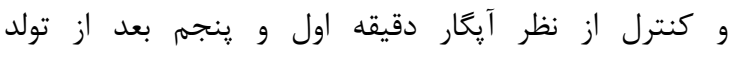

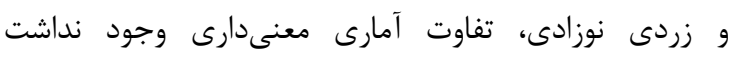

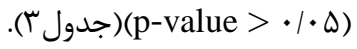

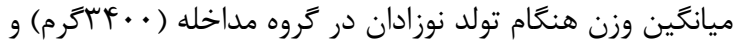

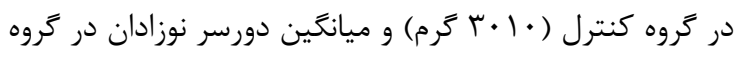

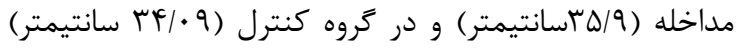

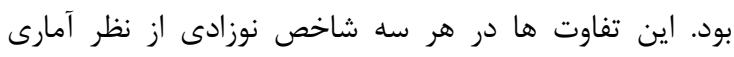

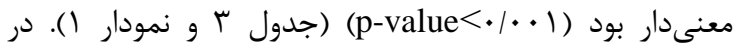

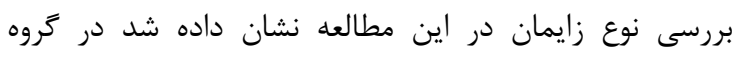

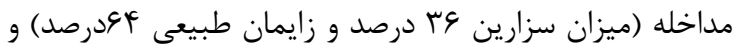

\begin{tabular}{|c|c|c|c|c|c|c|}
\hline \multirow{3}{*}{ آزمون مربوطه } & \multirow{3}{*}{ p-value } & \multicolumn{4}{|c|}{ كروه هاى مورد مطالعه } & \multirow{3}{*}{ ييامد مادرى و نوزادى } \\
\hline & & \multicolumn{2}{|c|}{ كروه كنترل } & \multicolumn{2}{|c|}{ تروه مداخله } & \\
\hline & & انحراف معيار & ميانَين & انحراف معيار & ميانكين & \\
\hline آزمون تى مستقل & $\cdot / \cdots 1$ & $\cdot 109$ & $r \cdot r \cdot$ & $\cdot / 4 \wedge$ & $r F .$. & وزن هنگام تولد \\
\hline آزمون تى مستقل & $.1 \cdots 1$ & $r / 4$ & FN/9 & $r / 94$ & $\Delta T / 1$ & قد هنغام تولد \\
\hline آزمون تى مستقل & $.1 . .1$ & 1/AD & $r F / \cdot 9$ & $r / \Lambda \Lambda$ & $r \Delta / 9$ & دورسر هنكام تولد \\
\hline آزمون تى مستقل & $\cdot / 4 \wedge \Delta$ & $\cdot / 4$ & $1 / 9$ & $\cdot 11$ & $9 / 5$ & آيخار نوزاد در دقيقه اول تولد \\
\hline آزمون تى مستقل & .1019 & 1/9 & 1. & $\cdot / V$ & 1. & آيكار نوزاد در دقيقه پِنجم تولد \\
\hline آزمون كاى دو & $\cdot / 1 \cdot 4$ & $\cdot / 4$ & $r$ & $\cdot / 4$ & r & زردى نوزادى \\
\hline \multirow{2}{*}{ آزمون كاى دو } & \multirow{2}{*}{$.1 . \cdot 1$} & | & ra & | ل أودرصد & i^ & زايمان طبيعى \\
\hline & & r r/r/مدرصد & r. & ع عادرصد & tr & زايمان سزارين \\
\hline
\end{tabular}

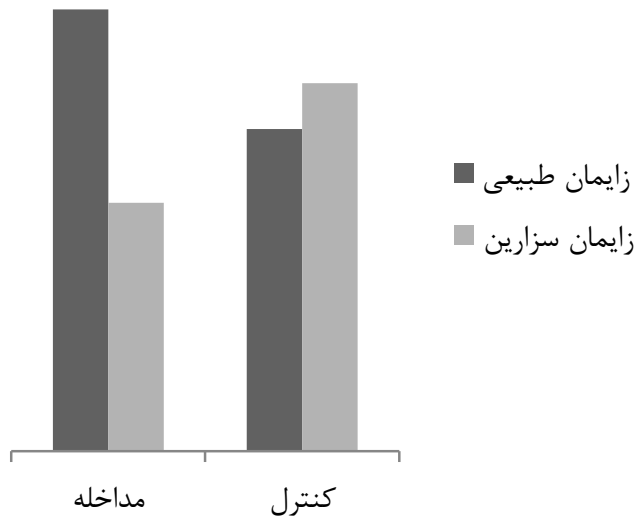

نمودار ؟: مقايسه نوع زايمان در دو گروه مداخله و كنترل

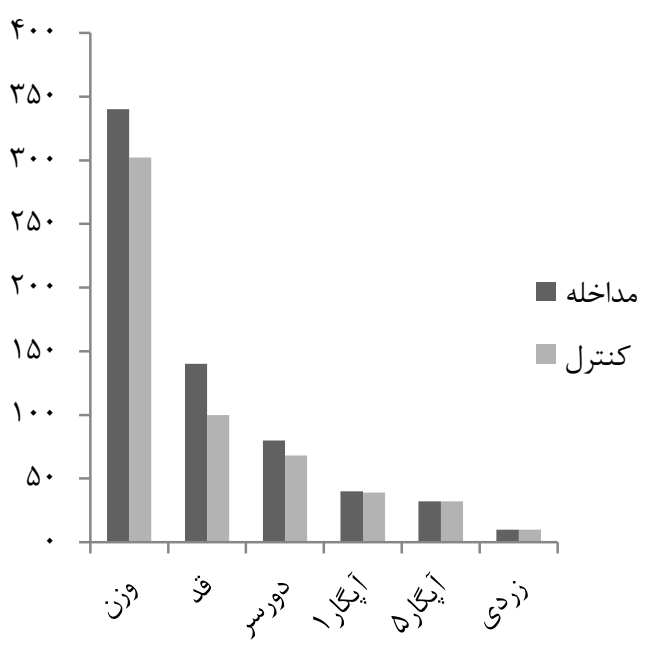

نمودار ا: مقايسه يِيامد نوزادان در دو گروه مداخله و كنترل
ومير و عوارض ناخواسته هنگام زايمان همراه است [Yr].

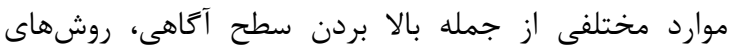

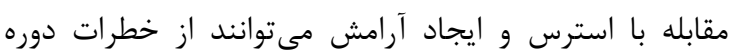

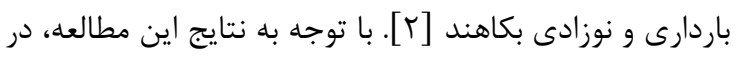

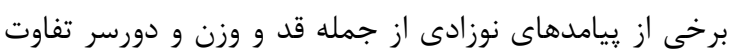

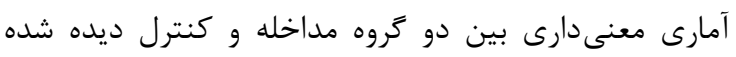

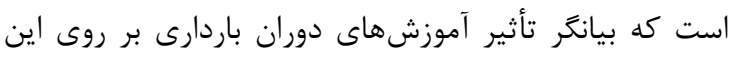

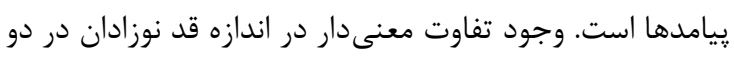

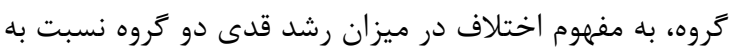

با وجود اينكه در زنان باردار گروه يرخطر احتمال افزايش

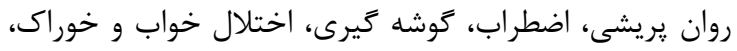

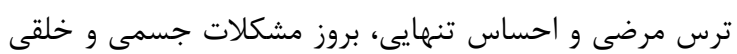

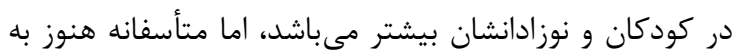

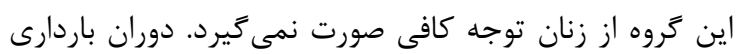

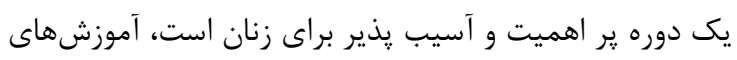

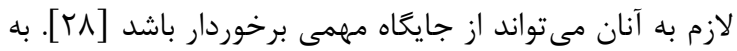

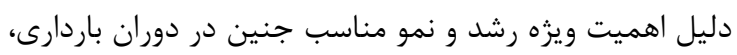

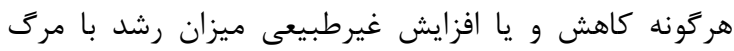


باردار موجب بهبود ضريب آيخار در دقيقه اول و ونجمه بعد از إز

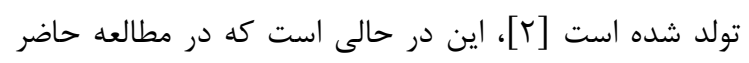

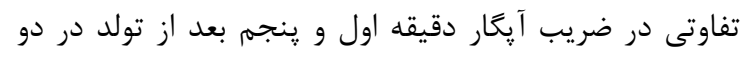

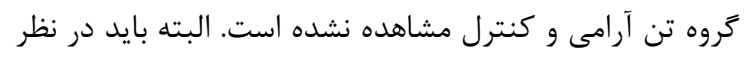

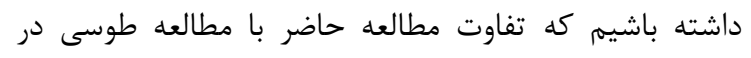

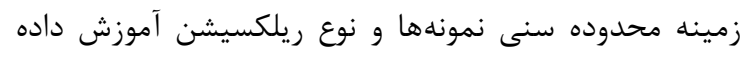

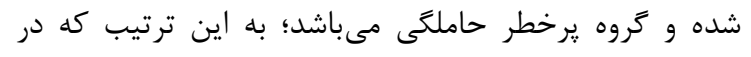

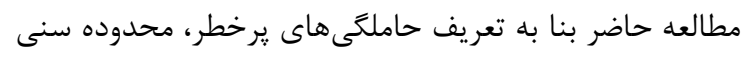

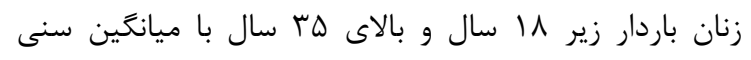

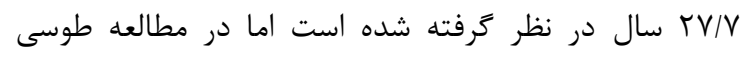

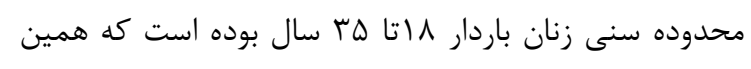

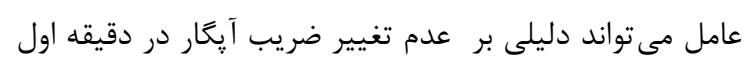

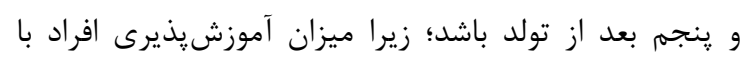

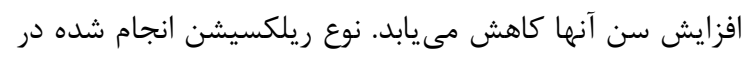

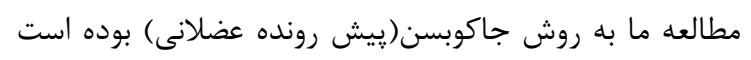

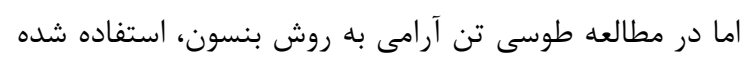

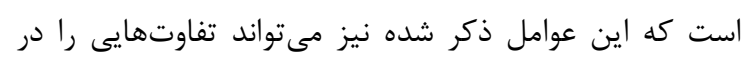

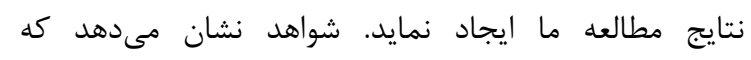

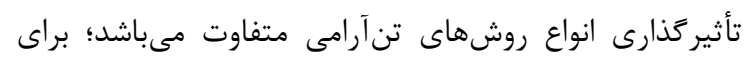

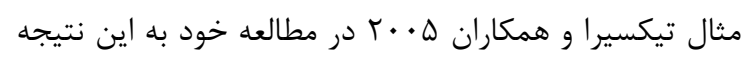

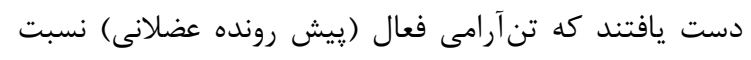

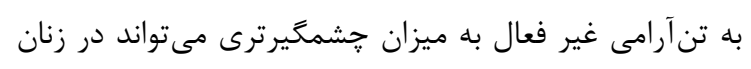

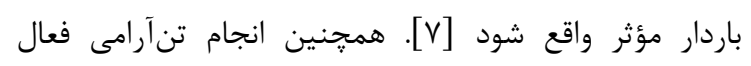

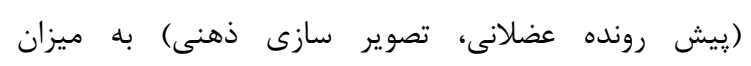

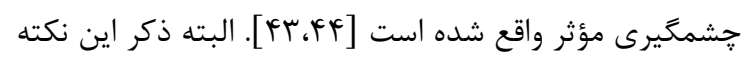

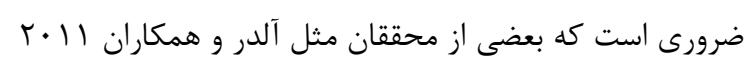

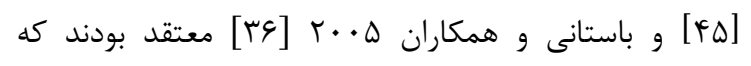

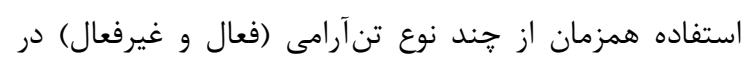

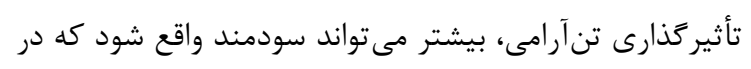

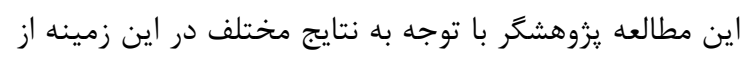

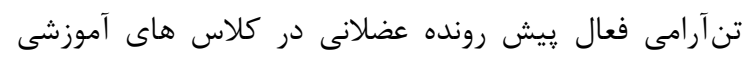

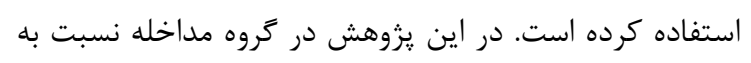

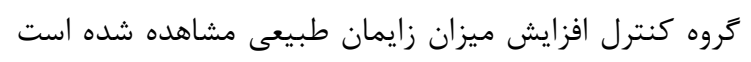

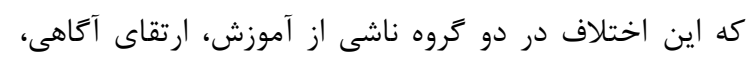

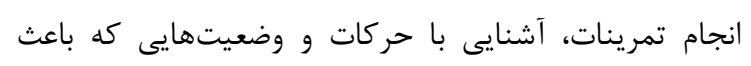

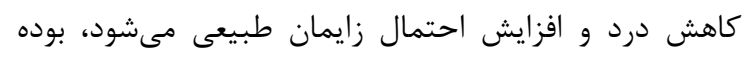

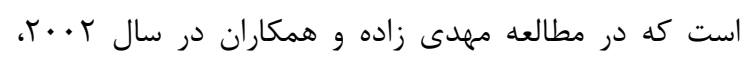

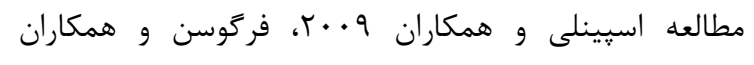

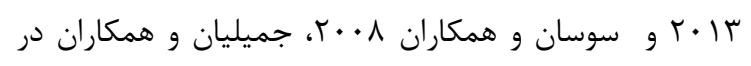

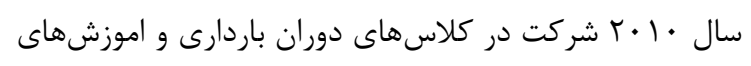

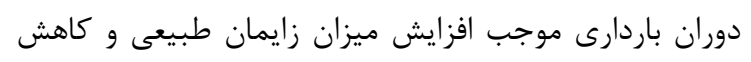

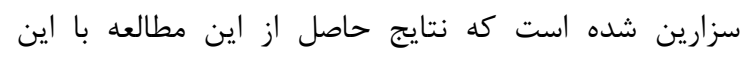

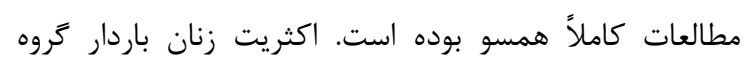

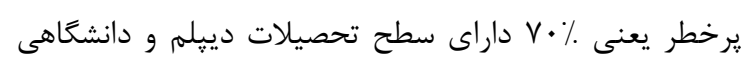

هم است كه مىتواند ناشى از تأثير اين آموزشها باشد.

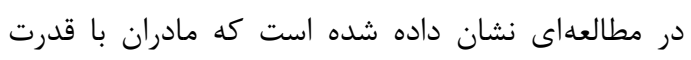

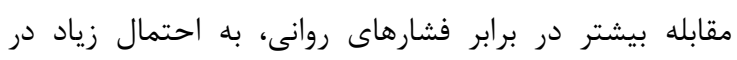

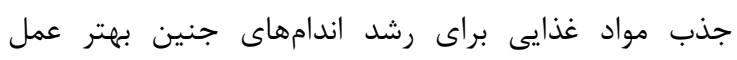

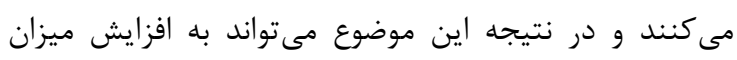

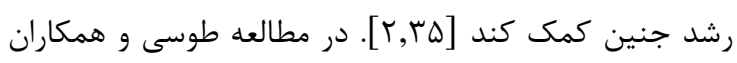
Y

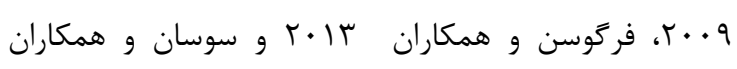

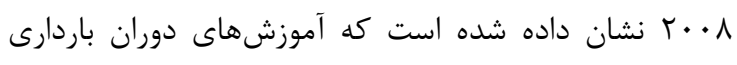

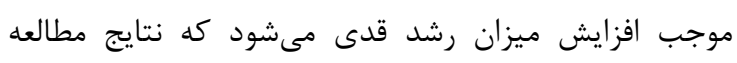

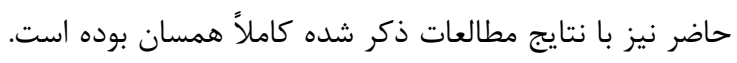

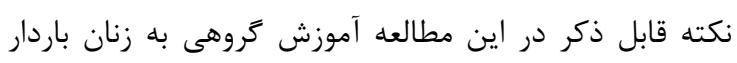

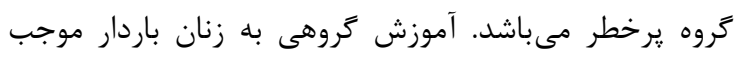

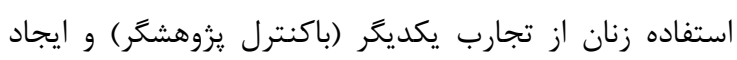

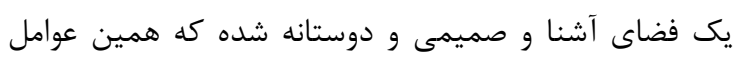

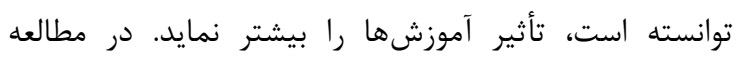

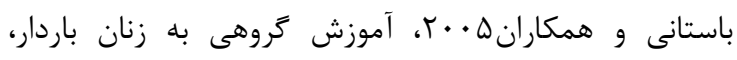

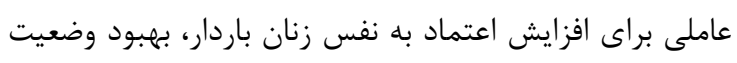

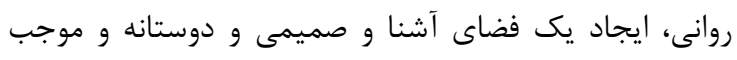

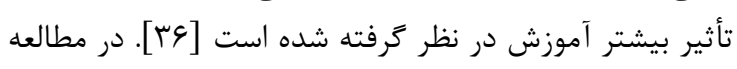

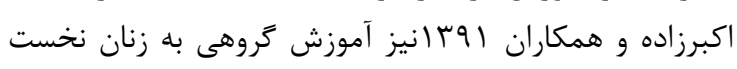

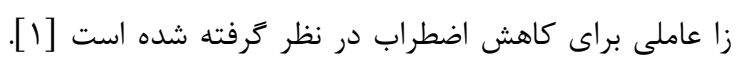

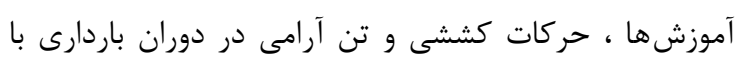

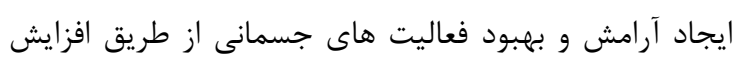

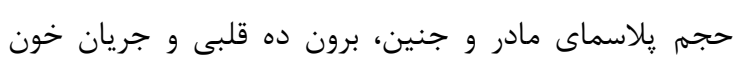

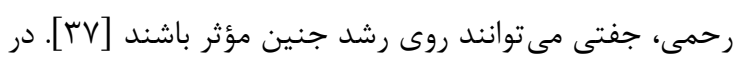

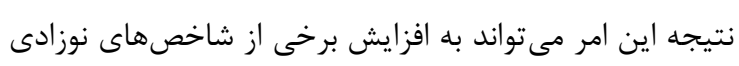

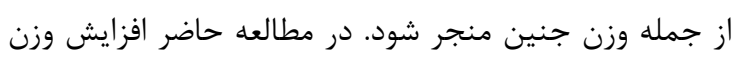

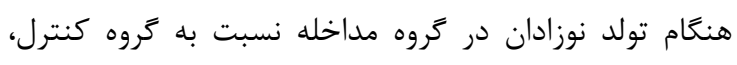

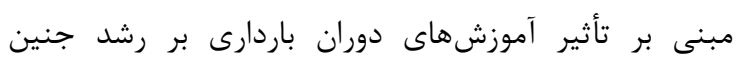

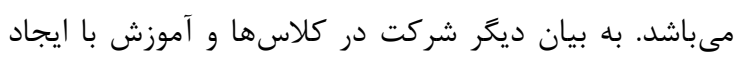

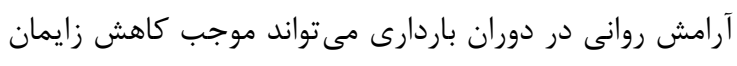

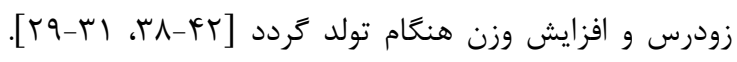

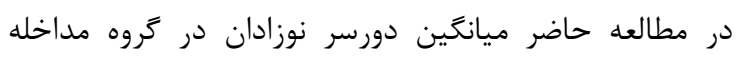

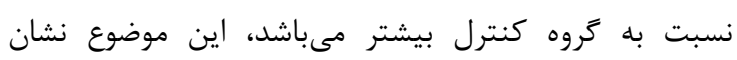

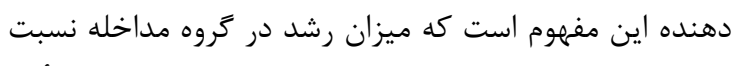

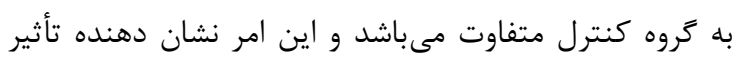

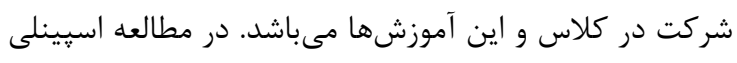

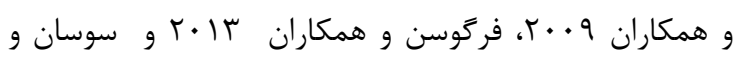

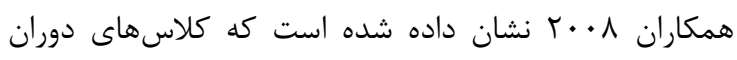

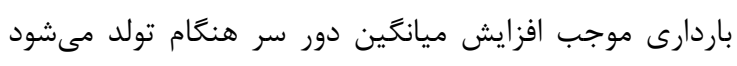

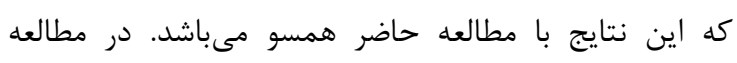

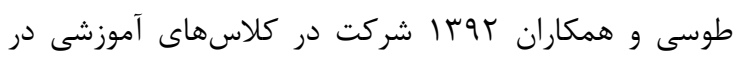

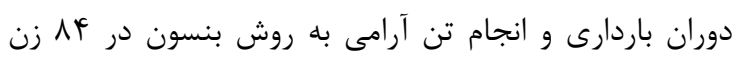




$$
\begin{aligned}
& \text { با بهبود يِيامد نوزادان افزايش قد و وزن و دورسر و افزايش }
\end{aligned}
$$

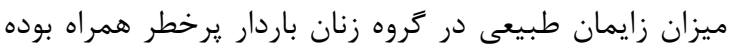

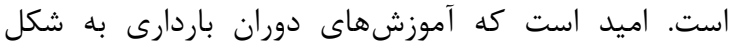

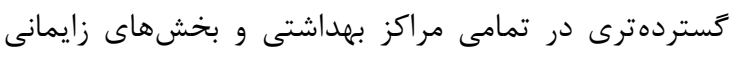

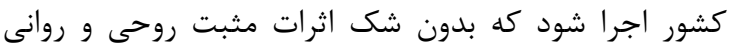

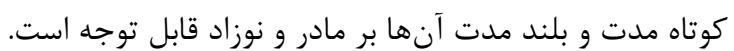

$$
\text { تشكر و قلرواذى }
$$

اين مقاله حاصل پايان نامه كارشناسى ارشد مامايى

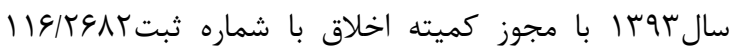

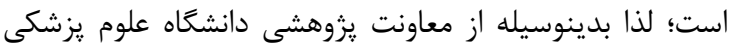
شهيد بهشتى شعبه بين الملل، مركز سلامت مادران، مراكز

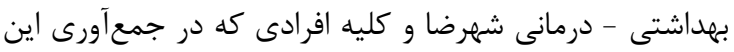

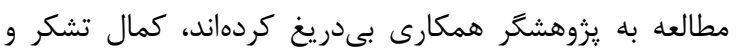
قدردانى مى گردد.

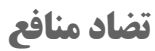
اين مطالعه براى نويسنده هيجزَّنه تضاد منافعى نداشته

\section{REFERENCES}

1. Akbarzade M, Toosi M, Zare N, Sharif F. Effect of Relaxation and attachment behaviors training on anxiety in first-time mothers in Shiraz city: A randomized clinical trial. Qom univ med SCIJ, 2013;6(4): 14-23. (Persian)

2. Toosi M, Akbarzadeh M, Zare N, Sharif F. The role of relaxation training in health index of infants in pregnant mothers. Journal of jahrom University of Medical Sciences, 2013;11(1): 15-21. (Persian)

3. London M, Ladewig P, Ball J, Bindler R, Maternal and child nursing care, 2th ed. upper saddle River: pearson prentice hall;2007.

4. Warren SL, Racu C, Gregg V, Simmens SJ. Maternal paniv disorder:infant prematurity and low birth weight. J Anxiety Disord, 2006; 20: 342-352. DOI: 10.1016/j.janxdis. 2005.02.007

5. Shahhosseni Z, Abedian K, Azimi H.Anxiety during pregnancy in preterm delivery.Zanjan univ Med SCIJ, 2007;16 (63): 85-92. (Persian)

6. Alipoor Z, Lamyianm M, Hajizade E. Anxiety in pregnancy: Risk for outcome child birth. oromiee univ med SCIJ, 2009;9(1): 30-38. (Persian)

7. Teixeira J, Martin D, Prendiville O, Glover V. Theeffects of acute relaxation on indices of anxiety during pregnancy .J Psychosom Obstet Gynaecol, 2005 ;26:271-276. PMID: 16457423

8. Saif S, Kadivar P. Growth psychology $4^{\text {th }}$ ed. Tehran: Roshd publication; $1884-87$

9. Mosavi Asl SA, Khramin SHA, Hadinia A, Rakhsha SHR, Poursamad A. The Role of Relaxation Training to pregnant Mothers on Health Index of Infants .J Armaghan danesh, 2009; 14(2): 97-104. (Persian)

10. Oates MR. Adverse effects of maternal antenatal anxiety on children: causal effect or developmental continuum? Br J Psychiatry, 2002; 180:478-9. PMID:12042222

11. Shayeghiyan Z, Rasolzade K, Sedighi E. Effect Anxiety in pregnant women on delivery and health infants. Tehran univ Med SCIJ, 2007; 14(3): 57-64. (Persian)

12. Adibnegad R. In translation: Pediatric physician, growth and nutriation. $17^{\text {th }}$ ed.:Hay. Tehran an publication, 2004; 323-
و. • • از زنان باردار خانهدار بودهاند كه همين موارد مىتواند تأثير حذارى آموزش هاى دوران باردارى را در زنان باردار بيشتر نمايد. قابل ذكر است در مطالعه باستانى و همكاران [عr] و تيكسيرا و همكاران [V] نيز سطح تحصيلات و خانهدار بودن مادران باردار نيز عاملى مهم در تأثير گذارى بيشتر آموزشهاى دوران باردارى ذكر شده است.

محدوديت موجود در يروهش حاضر شامل، با توجه به تأثير عوامل محيطى نظير ميزان سواد، شرايط اقتصادى و ودودئ ويزگى ها و عادات خاص زندگى در زنان مختلف و تأثير آنها بر روى ميزان اثر آموزش هاى دوران باردارى سعى شد شد كه نمونه ها از لحاظ موارد ذكر شده، همگًن و همسان باشند و بان انتخاب نمونهها به طور تصادفى، اثر اين نوع محدوديت را به

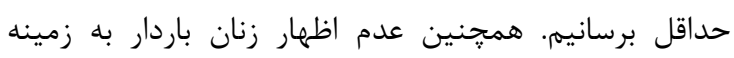

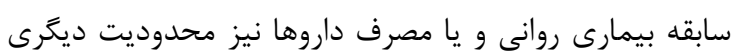

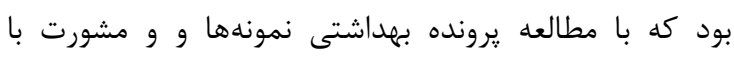
يزشك و ماماى مركز سعى شد كه اثر اين نوع محدوديت را به به به بهون حداقل برسانيم.

\section{نتيجهم تميرى \\ در اين مطالعه اجراى برنامه آموزشى در دوران باردارى}

13. O'Connor TG, Heron J, Glover V, The LASPAC Study Team. Antenatal anxiety predicts child behavioral/emotional problems independently of postnatal depression. J Am Acad Child Adolese Psychiatry, 2002;41: 1470-1477. doi:/10.1097/00004583-200212000-00019

14. Okour AM, Badarneh R. Spousal Violence against Pregnant women from a Bedouin Community in Jordan. J Womens Health [Larchmt], 2011; 20(12): 1853-9. PMID:21870963 DOI: $10.1089 /$ jwh.2010.2588

15. Brownridge DA,Taillieu TL, Tyler KA, Tiwari A, Ko ling $\mathrm{CH}$, Santos SC. Pregnancyand intimate partner violence: Risk factors,severty,and health effects. Violence Against Women, 2011 ;17(7): 858-881. PMID: 21775311. DOI: $10.1177 /$ 1077801211412547

16. Akbarzade M.Mental Health in Pregnancy \&Child birth. $9^{\text {th }}$ ed.Hydari publishers Tehran; 2012.pp: 21-98. (Persian)

17. Azizi A. Frequency of high risk pregnancy causes in pregnant women. Iranian Journal of Obstetrics and Gynecology. 2015:18(153): 10-19.

18. Towle MA .Maternal \&newborn nursing care.13th edition: United States of American pub.2009.pp347.

19. Beers MA, Porter KS, Jones TV, Kaplan JL, Berkwits M. High risk pregnancy .lucile Packard children hospital at Stanford.Disease Health Info/HealthLibrary.2011.pp 246.

20. Mirzaee F. High risk pregnancy.33rd edition.tehran:nore andishe pub, 2009.pp78. (Persian)

21. Rahimi F, Ahmadi M, Rosta F, Alavi Majd H, Valiani M. Effect of Relaxation Training on Pregnancy Anxiety in High Risk Women .journal of safety promotion and injury prevention 2014;2(3):180-189. (Persian)

22. Jamilian M, Mobasseri SH, Wakilian K, Jamilian H R. Effect of childbirth preparation classes on the duration of admission and satisfaction of mothers. Scientific journal of Ilam University of medical Sciences, 2012; 21(2), 44-50. (Persian)

23. American Academy of pediatrics and the American college 
of obstetricians and Gynecologists: Guidelines for perinatal care .Disk-Read G, editor.4th ed.ACOG :Washington DC;2004.

24. Saisto T,Toivanen R,Salmela-Aro K,Halmesmaki E.Therapeutic group psychoeducation and relaxation in treating fear of childbirth.Acta Obstet Gynecol Scand, 2006 ;85:1315-1319.

25. Bahrami N ,Araban M ,Bahrami S.The impact of antenatal education on postpartum depression, Dezful ,Iran: Hormozgan univ med SCIJ, 2009;13(4): 277-283.(Persian)

26. Mehdizadeh A, Roosta F, Kamali Z, Khoshgoo N. Evaluation of the effectiveness of antenatal preparation for childbirth courses on the health of the mother and the newborn. Razi Medical Journal, 2003:10(35), 455-461. (Persian)

27. Wetzel W. Alternative and complementary therapies. Maternity and women's health care. $8^{\text {th }}$ ed.Maryland: Mosby; 2004:74-90. PMID: 25268759. PMCID: PMC4195350. DOI:10.1089/jwh.2013.4568

28. Maknney ES, James SR, Murray SS,Ashwill JW. Maternal child nursing. $3^{\text {rd }}$ ed. Philadelphia: Saunders; $2008:$ pp33.

29. Spinelli G, Baglio S, Donati ME, Grandolfo J. Osborn. Do antenatal classes benefit the mother and her baby? The Journal of Maternal-Fetal \& Neonatal Medicine, 2009;13(2): 94-101. Doi:10.1080/jmf.13.2.94.101

30. Ferguson S, Davis D, Browne J. Does antenatal education affect labour and birth? A structured review of the literature, 2013;26(1): 5-8

31. Susan K. McGrath, John H, Kennell MD. A Randomized Controlled Trial of Continuous Labor Support for MiddleClass Couples: Effect on Cesarean Delivery Rates, 2008;35(2): 92-97.

doi: 10.1111/j.1523-536X.2008.00221.x

32. Artieta Pinedo I, Paz Pascual C, Gurutze RemiroFernandezdegamboa G, Odriozola-Hermosilla I Bacigalupe A, Payo J. The Benefits of Antenatal Education for the Childbirth Process in Spain.2010; 29(3). DOI: 10.1097/NNR.0b013e3181dbbb4e

33. Bstani Khalesi Z, Rafat F, Pakseresht S. Relationship between adequacy of prenatal care utilization index and neonatal outcomes.2013;25(76): 8-15. (Persian)

34. Cunningham FG. Leveno KJ, Bloom S, Hauth J, Rouse D, Spong C. Williams obstetrics. $23^{\text {rd }}$ edition .2010 .Newyork :MCGraw،Hill

35. Kali RV, Cavanaugh JC. Humman development $.2^{\text {nd }}$ ed.Belmot CA: Wadsworth publ ; 2000 :93 -5.
36. Bastani F, Hidarnia A, Kazemnejad A, Vafaei M, Kashaian M. Arandomized controlled trial of the effects of applied relaxation training on reducing anxiety and perceived stress in pregnant women , American college of nurse'midwives issued by Elsevier Inc,2005; 50(4):36،40. (Persian)

37. Clapp JF. The effect of maternal exercise on fetal oxygenation and fetorplacental growth .Eur J Obstet Gynecol Reprod Biol. 2003; 110(11): 80-5. PMID:12965094

38. Mosavi asl SA, Khramin SHA, Hadinia A,Rakhsha SHR, Poursamad A. The Role of Relaxation Training to pregnant Mothers on Health Index of Infants .J Armaghan danesh $2009 ; 14[2]: 97 ، 104$. (Persian)

39. Bastani F, Hidarnia A, Montgomery KS,Aquilar،Vafaei ME, Kazemnejad A. Dose relaxation education in anxious primigravid Iranian women influence adverse pregnancy outcome ?A Randomized controlled trial. J Perinat Neonatal Nurs 2006;20:138-146. (Persian)

40. 40-Fink N,Urech C,Cavelti M, Alder J.Relaxation during pregnancy: what are the benefits for mother, fetus, and the newborn?A systematic review of the literature.J Perinat Neonat Nurs 2012 ;26[4]:296-306. PMID:23111717. DOI:10.1097/JPN.0b013e31823f565b

41. Omer H, Friedlander D, Palti Z. Hypnotic relaxation in the treatment of premature labor. Psychosom med 1986 ;48:351-361. PMID:3523570

42. Chuntharapat S, Petpichetchian W, Hatthakit U. Yoga during pregnancy: effects on maternal comfort,labor pain and birth outcomes. Complement ther clin pract 2008;14:105-115. PMID:18396254.DOI:10.1016/j.ctcp.2007.12.007

43. Urech C, Fink NS, Hoesli I, Wilhelm FH, Bitzer J, Alder J. Effect of relaxation on Psychobiological Wellbeing during pregnancy: A Randomized controlled trial. Psychoneuroendocrinology $2010 \quad ; 35: 1348-1355 . \quad$ PMID: 20417038. DOI:10.1016/j.psyneuen.2010.03.008

44. Rahimi F, Ahmadi M, Rosta F, Alavimajd H, Valiani M, Kahangi S M M. Investigating the Effect of Progressive Muscle Relaxation Training on Infants outcome in High Risk Pregnant Women . sjimu. 2018; 25 (6) :10-20 (Persian)

45. Alder J, Urech C, Fink N, Bitzer J, Hoesli I. Response to Induced relaxation during pregnancy:comparison of women with High Versus Low Levels of Anxiety. J Clin Psychol Med Settings2011;18:13-21. PMID:21225321.DOI:10.1007/ s10880-010-9218-Z 